\title{
Free daily newspapers: Professional norms, business model and routinized production in the metropolis
}

\author{
Guest Editorial Committee: \\ Audrey Alves, University of Lorraine, Centre de recherche sur les médiations - Crem \\ Loïc Ballarini, University of Lorraine, Centre de recherche sur les médiations - Crem \\ Christian Lamour*, Luxembourg Institute of Socio-Economic Research - LISER \\ *Corresponding author: christian.lamour@liser.lu
}

Free daily newspapers such as Metro and 20 Minutes were published for the first time two decades ago. Today, they are part of the media market and they are read every day by hundreds of thousands of urbanites in metropolitan regions. These dailies are often presented as a symbol of the transformation of the press. But they attract a limited interest from communication scholars. Following the international conference named "The free daily press in Europe. 1995-2015" and organized by the CREM Research Unit and LISER in March 2016, we considered that a thematic section in SComS would be a good opportunity to present a series of double-blind peer reviewed articles dedicated to this media from three perspectives: Professional norms, business model, and geographical issues.

The first article is dedicated to one central question: Can free dailies be associated with quality journalism? Kirsten Sparre from the University of Aarhus takes the case study of MetroXPress distributed in Denmark and owned by the Swiss group Tamedia. She considers three criteria to assess the qualitative value of the journal: The recognition of its work by public authorities and by the rest of the profession, plus the sources of information used in the production of articles. The investment made by the journal in terms of journalistic resources and the interactions between the newspaper and its environment signal that free dailies can be recognized for the professionalism of their reporters.

The second article is focused on the main objective of these media. That is the profitability to its editorial group by selling the attention of readers to advertisers. Michael Dahan and Mouli Bentman from the Sapir College of Jerusalem argue that not all free dailies are circulated to become a profitable business for their owners. Their analysis of Yisrael Hayom, also nicknamed "Bibiton " in Israel or the journal of the prime minister Benjamin Netanyahou, shows that the most read newspaper of the country three years after its launch in 2007 is still in deficit in 2016; its owner the American businessman Sheldon Adelson being obliged to invest between one and two million dollars per month in the daily. The success of this newspaper in terms of public is explained by its excellent distribution and especially by its ability to attract a specific readership in the country: the young Israeli doing their military service. This free newspaper is an economic failure, but it also disturbs the whole media market in the country by proposing economic deals to advertisers twice more advantageous than the ones offered by the other media. The two researchers show that the free daily press can have other motives than pure economics and play a key role in the mediated public sphere.

The last article is dedicated to the role of the free dailies in the definition of metropolitan regions in which they are distributed. The purpose is to find out how the interactional routines of free dailies professionals and the production of contents is related to the organization of the large cities in the late modern era. Christian Lamour from the Luxembourg Institute of Socio-Economic Research (LISER) carries out this analysis by considering the newspaper 20 Minutes distributed in 
French-speaking Switzerland and more precisely in the metropolis of the Leman Lake. He shows how the routinized production of articles and adverts in this free daily is both located in a metropolitan space of flows and in the inherited space of bounded territories of the Swiss Confederation. New producers and commercial agents of the free daily determine their daily activities in a metropolitan region structured by networks and borders to secure the best attraction possible of publics and advertisers. It turns out that some institutional and cultural borders of the past can strongly contain the lifeworld of media professionals in the seemingly debounded metropolises of the late modernity. 